$\S=-1$

\title{
The Importance of Post-Activation Potentiation (PAP) Training on Physical Fitness Preparation for Malaysian Female Hockey Players
}

\author{
Kassim Mohar, Rahman Fariq \\ ${ }^{I}$ The Center for Coaching Science, National Defense University of Malaysia \\ *Corresponding author Email: mohar@upnm.edu.my
}

\begin{abstract}
A vast amount of research has been performed illustrating that the execution of certain conditioning activities at maximal or nearmaximal intensities can acutely enhance subsequent athletic performance with given sufficient recovery. This phenomenon is known as post-activation potentiation (PAP) and its use within the field of strength and conditioning has grown rapidly as performance enhancing effects have been demonstrated within athletic movements such as jumping and sprinting. Objective: The purpose of this study is to analyse the effectiveness of PAP training on sprint performance and power production among Malaysian female hockey player. Methods: A total of 18 well-trained athletes (age $25 \pm 3.7$; mass $54 \pm 4.9$; height $160.8 \pm 2.8$; relative strength half-squat $1.9 \pm 0.3$; relative strength hex-bar deadlift $1.7 \pm 0.5$; relative strength hang clean $0.8 \pm 0.1$ ) were tested for 20 meter sprint time and counter-movement jump (CMJ) test during the preparation phase. This study used two different groups such as experimental group (EG) and control group (CG) and each player were randomly assigned. Both groups were completed training in twice per week for a period of eight week training program. The EG performed a total of 16 session by having 2 different training blocks. Each block has a period practice of training for 4 weeks and each block also has different types of exercise. Meanwhile, CG completed 16 session based on coach training program and did not practice at the same time with the EG. The study intervention program including pre-test and post-test activities were conducted before and after the study. Result: A data analysis of paired t-test and independent t-test was used and the level of significance in all statistical analyses was set at $\mathrm{p} \leq 0.05$. The result showed that 8-weeks of EG displayed significantly improved in sprint performance $(\mathrm{p} \leq 0.005)$ and power production $(\mathrm{p} \leq 0.005)$. Moreover, result also revealed a significant difference between EG and CG in sprint performance $(\mathrm{p} \leq 0.000)$ and power production $(\mathrm{p} \leq 0.008)$. Conclusion: In short, the result emphasized the contribution of kinetic and kinematic parameters for sprint and power performance. The EG result seem significant for athletic performance. Therefore, this findings is of great practical interest for coaches and fitness trainers and relevant to female hockey players and consequently maybe used in training program.
\end{abstract}

Keywords: Post-activation potentiation, maximal acceleration, lower body power, female hockey

\section{Introduction}

Presently, many of us are looking for a highly efficient and quality resistance training program. New training methods are constantly being produced, or old methods are modified and recycled. For the researchers, strength and conditioning professionals and personal trainers, the effectiveness of any resistance training is their main goal. As a result, research on resistance training and training strategies lot of progress.

Since it was reported in the '90s, there has been significant practical interest in the idea that the performance of maximal or near maximal of muscle contraction may increase the strength and power production in subsequent exercise. This phenomenon called post-activation potentiation (PAP) [1].

A considerable amount of literature has been published on the definition of post activation potentiation (PAP). In 2005, Robinson [2] reported that the PAP phenomenon is the immediate muscle force output of explosive movements after a heavy resistance exercise is performed. As noted by Alexander [3], PAP is the performance phenomenon in which a person acutely performs an intense, externally loaded exercise and then afterward performs with greater muscular force producing characteristics.

Similarly, Smith [4] stated that the post-activation potentiation mechanism seen to increase neuromuscular state after the execution of a high-intensity exercise. Up to now, studies on the PAP is still more to be done, and the definition of PAP can be defined as the execution of certain conditioning activity at maximal or near-maximal intensities can acutely subsequent athletic performance given sufficient recovery [5].

There is a large volume of literature has been published on postactivation potentiation (PAP). These studies documented that PostActivation Potentiation (PAP) has been shown to provide an ergogenic effect to athletic performance under certain conditions [6-9].

When studying the physiological aspects, there are some reactions that occur when the underlying this activity. Among them increase in motor unit recruitment, increased muscle spindle firing, development activity of the synergist musculature, and lessen inhibition of the Golgi tendon organ [10]. In addition, the PAP phenomenon can potentially maximize the performance of explosive based activities such as sprinting, jumping and throwing 
activities [10-11]. When examining in greater depth, especially talking about physiology that contributes to PAP, there are two proposed theories for PAP.

According to Hodgson [12], the first theory is related to within muscle. It involves an increased phosphorylation of myosin during a maximum voluntary contraction (MVC). This allows the actin and myosin binding be more responsive to the calcium ions released from the sarcoplasmic reticulum [13]. Thus, it will lead to enhanced force muscle production at the structural level of muscle [14]. In their clinical analysis, Rison et al. [15] conclude that the greater activation, the greater duration of calcium ions in the muscles cell environment and the greater the phosphorylation of the myosin light chain protein. As a result, faster contraction rates and faster of tension develop [16].

The second theory involves the Hoffmann Reflex (H-Reflex), named after the scientist (Paul Hoffmann) who first described it. By drawing on the concept of mechanism attributed to PAP, [17] has been able to show that the H-reflex is a reaction of muscles after electrical stimulation of sensory fibers that involves type II or fast twitch fibers which respond to the rate of change in muscle length as well to change in velocity and rapidly adapting. It is theorized that the PAP intervention enhances the H-reflex, thus increasing the efficiency and rate of the nerve impulses to the muscle $^{12}$.

It is noticeable that the post-activation potentiation training program was designed to upgrade overall athlete's physical performance, rather than to increase strength maximally. Components of speed, agility, strength, aerobic and anaerobic energy system is an advanced high requirement for athletes on the competition. By empathetic how the contractile properties of muscle fibers, it can domination performance and provide coaches and athletes with extra alternatives when drawing training program.

Planning and deciding an ideal quality strength program is dependably challenge for athletes, coaches, and physical conditioning experts. In general, the resistance training that targeting to increase the strength is requires subject to lift up heavy intensity and less training volume, while the objective to elevate the power entail to apply the highest force in the shortest time [18]. Consequently, the main purpose of an impactful resistance training program is to boost up the power and strength performance simultaneously, which can be practiced by applying a high force with combination rapid force movement. The use of PAP in training session is typically called complex training (CT) [19-21]. $\mathrm{CT}$ is considered a very beneficial training program for developing power, since it alternates high load weightlifting movements with biomechanical similar motion in the same drills. The success of the training complex theory has been generally described in paragraphs beginning. Where it involves the physiological structure of the body such as muscles and the nervous system. To create successful strength training program, the implementation of periodization has been shown to improve power and strength in both males and females, regardless of training experiences [22-23]. According to Rehea et al, [24], there are two types of periodization models that commonly used such as linear and undulating. Both models revealed the improvement of strength capacity [23-25]. Some authors said, linear give significantly in strength development [26-27] and undulating periodization model can provide a more advantages improvement in power strength [27-28]. However, whether linear or undulating, both of which can give the best impression of the performance.

According to Jose et al, [29], strength training must be integrated with sport skills training to improve skill performance. Although this exercise has demonstrated some practical merit, there is often little research evidence to scientifically support their effectiveness. Therefore, better designed and controlled research in this studies are warranted $^{18}$.

\section{Method}

Subject: For this experimental study, the researchers have used national hockey players as experimental. With the character of the team is very satisfying as weight training techniques, quality playing experience, balanced in tactical play and mental preparation, this study would be fairly homogeneous in term of athletic development and have a mature group of subjects.

All of them are in competition phase. This study consists of 18 female hockey players who are involve in the same team compete in competition. Average age of the subject was $25 \pm 3.7$ years old and have a minimum of 5 years' experience in the field hockey game.

Exclusion criteria were designed as a part of the study methodology. Subjects were exclude from the study to failing to meet any of the following criteria, any player with a recurrent injury in details musculoskeletal injury over 10 days was excluded from the recruitment phase of the study. Secondly, any player who had suffered an illness such as fever, headache and vomiting in the 2 days before the training intervention session start was excluded.

Procedure: The study took 10 weeks including pre and post-test activities were conducted before and after the study. The anthropometric measurement was collected first, followed by physiological data. Before the players are allowed to start interventions, they will do a $1 \mathrm{RM}$ strength test like half-squat, deadlift and power clean. The 1RM testing was implemented 1 week before the experimental session start. To start the 1RM test, players completed a standardized warm-up including 2 minutes of cycling on stationary bicycle and a series of hip mobility exercise (e.g. goblet squat and glute-bridge).

Next, the players performed a specific back squat warm-up consisting of 10 repetitions with a $20 \mathrm{~kg}$ unloaded bar, then begin testing with 6 repetition s at $40 \%, 4$ repetitions at $60 \%$ and 2 repetitions at $80 \%$ and 1 repetition at $90 \%$ of their estimated 1RM. One minute's recovery was given after the unloaded warm-up set, 2 minutes after the $40 \%$ and $60 \%$ and 3 minutes after $80 \%$ and $90 \%$. After three minutes rest of completed $90 \%$, the players were completed to attempts 1RM with 4 minutes recovery between attempts. The last successful attempt defined the player's 1RM. The load were increased based on the athlete's perception of the previous attempt. After the 1RM test, players practiced the experimental procedures.

Intervention: The periodized post-activation potentiation training required subjects in the experimental group to perform 16 training session within 8 weeks. Intervention session occurred every Monday and Thursday morning. Approximately 9 subjects were randomly chosen to take part in this experimental group. All the subjects have been afforded time to adapt this intervention. Each training session starts with a standardized warm-up and appropriate stretching.

The warm-up comprised two minutes of cycling on stationary bicycle and two set with 10 repetitions of hip mobility (e.g. mini band side walk, goblet squat and glute bridge) and back mobility exercise (thoracic spine rotation).

There are two training blocks used as a balancing exercise intensity. Each block has a period practice of training for 4 weeks and each block also has different types of exercise. The first block had an intensity of $85 \%-90 \%$ and the second block is $87 \%-93 \%$. In this experimental group, there are 3 additional exercise that intensity is $70 \%-75 \%$, and 2 set of 8 repetition only. For the control group, weight training will also be provided with the same number, 2 times a week. But, this type of training depends on the coach and the time training session is not the same. 
Table 1. Post-Activation Potentiation Program

\begin{tabular}{|c|c|c|c|c|c|}
\hline Block & Heavy Strength & Rest & Explosive Power & Volume & Intensity \% 1RM \\
\hline \multirow{6}{*}{1} & Back Squat & $4 \mathrm{~min}$ & Jumping Lunges & 3set $\times$ 5reps & \multirow[b]{2}{*}{$85 \%-90 \%$} \\
\hline & Hex-Bar Deadlift & $4 \mathrm{~min}$ & Drop Jump with Horizontal & 3set $\times$ 5reps & \\
\hline & \multicolumn{3}{|l|}{ Additional Exercise } & Volume & Intensity \% \\
\hline & Bench Press & $1 \mathrm{~min}$ & - & 2set x 8reps & \multirow{3}{*}{$70 \%-75 \%$} \\
\hline & Chin Up & $1 \mathrm{~min}$ & - & 1set $x$ 8reps & \\
\hline & Rear Foot Split Squat & $1 \mathrm{~min}$ & - & 2set $x$ 8reps & \\
\hline
\end{tabular}

\begin{tabular}{|c|c|c|c|c|c|}
\hline Block & Heavy Strength & Rest & Explosive Power & Volume & Intensity \% 1RM \\
\hline \multirow{5}{*}{2} & Back Squat & $4 \mathrm{~min}$ & Drop Jump with Horizontal & 2set $\mathrm{x}$ 4reps & $87 \%-93 \%$ \\
\hline & Hang Clean & $4 \mathrm{~min}$ & Double Leg Hurdle Jump & 2set $\mathrm{x}$ 4reps & \\
\hline & Dumbbell Chest Press & $1 \mathrm{~min}$ & - & 2set x 8reps & $70 \%$ to $75 \%$ \\
\hline & Dumbbell Row & $1 \mathrm{~min}$ & - & 2set $\mathrm{x}$ 8reps & \\
\hline & SL Glute Bridge & $1 \mathrm{~min}$ & - & 1set $x$ 8reps & \\
\hline
\end{tabular}

Measurement: The researchers was used Omron Body Weight Analyser as a tool in collecting anthropometric data. The anthropometric measurement included of height and weight of the body.

For physiological data, the two tests that were used such as 20 meter sprint test and counter-movement jump. For the 20 meter maximal acceleration, the purpose of this test is to assess the progress of the player's ability to effectively build up acceleration from standing start to a maximum velocity of running. The players should perform appropriate warm-up and stretching to avoid harm. Players must be in the ready position and feet do not exceed the line. The test is conducted 3 times and the assistant uses the fastest recorded time to assess the player's performance. Verbal encouragement from coaches, researcher and other players may allow in order to making players perform in more serious manner. The 20 meters time split is valid and reliable to measure the maximal acceleration performance of female's field hockey player.

Next is counter-movement jump. The counter-movement jump is primarily used to measure player's explosive lower-body power and has become one of the most frequently used tests by coaches and researchers to indirectly measure power in the lower body limbs. Players must complete 3 trials and the best score were collect.

Statistical Analysis: To view the results and the impact of 8 weeks of the experiment, the researchers have used scientific equipment such as SPSS (statistical package for the social science. This software was beneficial to measure and report the information that has been gathered. The data was set significant when $\mathrm{P}$ value $<0.05$. Data are shown as mean \pm $\mathrm{SD}$. The data were checked using Kolmogorav-Smirnov test in order to confirm either normal distribution or none. If information was in a normal distribution, parametric test were applied. The researcher will use Paired Sample t-test to compare the difference between pre and post-test. Secondly, researcher use Independent t-test to detect any difference between the experimental group and control group.

\section{Findings}

All subjects successfully completed the 8-week training intervention. The mean age of the subjects was $25 \pm 3.7$ years old and they managed to finish all the required training intervention and physical fitness test without any complication or injuries (Table 2).

Table 2. The characteristic of the subjects

\begin{tabular}{|l|l|}
\hline $\mathbf{N}=\mathbf{1 8}$ & (mean \pm SD) \\
\hline Age & $25 \pm 3.7$ \\
\hline Weight $(\mathrm{kg})$ & $54.0 \pm 4.9$ \\
\hline
\end{tabular}

\section{Height $(\mathrm{cm})$ \\ $160.8 \pm 2.8$ \\ Pre and Post Test of Experimental Group in Counter Movement Jump}

The table below displays the mean difference in pre-test and posttest in post-activation potentiation group. Interestingly, the postactivation potentiation group was observed to exhibit improvement from $32.26 \mathrm{~cm}$ in pre-test to $38.34 \mathrm{~cm}$ in post-test condition. The paired sample $t$-test shows that this training intervention provides a markedly significant impact, $t(8)=-6.50$, $p<0.005$, with PAP group yielding higher scores than the control group. The mean and standard deviation of pre-test is $32.26 \pm 4.2$ while the mean and standard deviation of post-test is $38.34 \pm 5.6$.

Table 3. Pre and Post Test of Experimental Group in Counter Movement Jump

\begin{tabular}{|l|l|l|l|l|l|}
\hline PAP Group & $\boldsymbol{N}$ & mean $\pm \boldsymbol{S D}$ & $\boldsymbol{T}$ & $\boldsymbol{d} \boldsymbol{f}$ & $\begin{array}{l}\text { Sig. (2- } \\
\text { tailed) }\end{array}$ \\
\hline Pre-test & 9 & $32.26 \pm 4.2$ & & & \\
\hline Post-test & 9 & $38.34 \pm 5.6$ & -6.504 & 8 & .000 \\
\hline
\end{tabular}

\section{Pre and Post Test of Experimental Group in 20 meter sprint}

The table below displays the mean difference in pre-test and posttest in post-activation potentiation group. Interestingly, the postactivation potentiation group was observed the improvement from 3.35 seconds in pre-test to 3.18 seconds in post-test condition. The paired sample $t$-test shows that this training intervention provided a markedly significant impact, $t(8)=8.32, p<0.005$ ). The mean and standard deviation of pre-test is $3.35 \pm .09$ while the mean and standard deviation of post-test is $3.18 \pm .05$.

Table 4. Pre and Post Test of Experimental Group in 20 meter sprint

\begin{tabular}{|l|l|l|l|l|l|}
\hline PAP Group & $\boldsymbol{N}$ & mean $\pm \boldsymbol{S D}$ & $\boldsymbol{T}$ & $\boldsymbol{d} \boldsymbol{f}$ & $\begin{array}{l}\text { Sig. } \\
(\mathbf{2} \text {-tailed) }\end{array}$ \\
\hline Pre-test & 9 & $3.35 \pm .09$ & & & \\
\hline Post-test & 9 & $3.18 \pm .05$ & 8.315 & 8 & .000 \\
\hline
\end{tabular}

Pre and Post Test between Experimental Group and Control Group in Counter Movement Jump

The table below illustrates the summary statistics of CMJ test between post-activation potentiation group and control group. The result of Independent t-test shown at the Sig. 2 tailed which stated that $t(16)=1.19, p>.251$ of the pre-test condition, and $t(16)=$ $3.04, p<.008$ of the post-test. The mean and standard deviation of pre-test in the post-activation potentiation group is $32.3 \pm 4.2$ while the control group recorded $29.7 \pm 4.8$. Afterwards, the mean and standard deviation of post-test in the post-activation potentiation group express improvement of $38.3 \pm 5.6$ while the control group showed only slight increase of $30.7 \pm 5.0$. 
Table 5. Pre and Post Test between Experimental Group and Control Group in Counter Movement Jump

\begin{tabular}{|l|l|l|l|l|l|l|}
\hline \multicolumn{2}{|c|}{ Group Training } & $\boldsymbol{N}$ & $\begin{array}{l}\text { mean } \\
\text { SD }\end{array}$ & $\boldsymbol{T}$ & $\boldsymbol{d} \boldsymbol{f}$ & $\begin{array}{l}\text { Sig. } \\
\text { (2-tailed) }\end{array}$ \\
\hline Pre-test & PAP G & 9 & $32.26 \pm 4.2$ & & & \\
\hline & CG & 9 & $29.72 \pm 4.8$ & 1.190 & 16 & .251 \\
\hline $\begin{array}{l}\text { Post- } \\
\text { test }\end{array}$ & PAP G & 9 & $38.34 \pm 5.6$ & & & \\
\hline & CG & 9 & $30.68 \pm 5.0$ & 3.042 & 16 & .008 \\
\hline
\end{tabular}

\section{Pre and Post Test between Experimental Group and} Control Group in 20 meter sprint

The table below illustrates the summary statistics of $20 \mathrm{~m}$ sprint test between post-activation potentiation group and control group The result of Independent $t$-test shown at the Sig. 2 tailed which stated that $t(16)=-1.87, p>.080$ of the pre-test, and $t(16)=$ $4.51, p<.000$ of the post-test. The mean and standard deviation of pre-test in the post-activation potentiation group is $3.35 \pm .09$ while the control group recorded $3.44 \pm .11$. Afterwards, the mean and standard deviation of post-test in the post-activation potentiation group express improvement of $3.18 \pm .05$ while the control group displayed only slight increase $3.38 \pm .12$.

Table 6. Pre and Post Test between Experimental Group and Control Group in 20 meter sprint

\begin{tabular}{|l|l|l|l|l|l|l|}
\hline \multicolumn{2}{|l|}{ Group Training } & $\boldsymbol{N}$ & mean \pm SD & $\boldsymbol{t}$ & $\boldsymbol{d f}$ & $\begin{array}{l}\text { Sig. } \\
(2-\text {-tailed) }\end{array}$ \\
\hline Pre-test & PAP G & 9 & $3.35 \pm .09$ & & & \\
\hline & CG & 9 & $3.44 \pm .11$ & -1.872 & 16 & .080 \\
\hline Post-test & PAP G & 9 & $3.18 \pm .05$ & & & \\
\hline & CG & 9 & $3.38 \pm 1.2$ & -4.515 & 16 & .000 \\
\hline
\end{tabular}

\section{Discussion}

This study sets out with the purpose of evaluating the effectiveness of producing post-activation potentiation training in physical fitness performance among female national hockey players. The primary aims of this research state that postactivation potentiation training provides significant outcome in acceleration sprint performance and lower body power production It disclosed that this rule of training has a positive impact on both the anaerobic system in maintaining the physical fitness of players during in-season competition.

In this context, the sprint test has been adopted as a measure of the acceleration performance of hockey players. In addition, Barun and Jvotsna [30] labelled the field hockey game as having frequent short sprints, direction changes, and acceleration-deceleration activities. Thus, the requirement of sprint, strength, and agility exercises are very essential aspects of field hockey training. Speed is the ability of individuals to perform movements consecutive quickly in a short time in accordance with a direction [31].

On the question of the effectiveness of post-activation potentiation training, this study found that the acceleration performance furnishes significant improvement after moving over 16 session $(8$ weeks) of post-activation potentiation training. The PAP group showed 5\% increment better than control group just only increase $2 \%$ as compared to between the pre-test and post-test. This result is in agreement with previous studies analysis of acute explosive training modalities to improve-body power in baseball players [32]. The study divided the subjects into 3 groups, namely complex training, resistance training and plyometric exercise. In addition, it took 15 weeks that were divided into 3 small blocks (5-weeks per block). The objective of the study was to see the impact of the training on 20,40, and 60 meters sprint, jump capacity, and agility test. As a result, a complex training set gives a very significant result over all the parameters being tested. These positive results have given a clearer picture on an acute study in post-activation potentiation training. In the latest study, Seitz [33] reported that doing a 20-meter sprint after 1 set of 3 repetition of back squats using a load of $90 \%$ of 1RM could have a good impact. Percentage increase can be seen in terms of sprint time $(2.16 \%)$, average velocity $(2.25 \%)$ and average acceleration $(4.59 \%)$ after getting 7 minutes rest time.

In contrast to the aforementioned findings, Bevan et al, [34] in his study about influence of post-activation potentiation on sprinting performance in professional rugby players noted that no significant improvements were found in 5 and 10 meters acceleration sprint. The subjects performed 3 single repetition of $91 \%$ from $1 \mathrm{RM}$ back squat and had resting time of $4,8,12$, and 16 minutes. This view is supported by Lim and Kong [35] who wrote that 1 set of 3 back squat at $90 \% 1 \mathrm{RM}$ with 4 minutes resting time revealed no significant change in sprint time over 10, 20, and 30 meters.

Considering all of this evidence, it seems that sprint performance can still be achieved through PAP training method. Exercises such as back squats and power clean are still relevant in giving stimulus to optimizing sports performance. This is proven when, Weyand et al, [36] through its study entitled, faster top running speeds are achieved with greater ground forces not more rapid leg movements stated that generating vertical force is important for maximal velocity sprinting. In addition, resting time is very sensitive to activate the PAP method. Resting time between 4 to 8 minutes are also encouraged.

Hockey is indeed a high-intensity sport. This sport does not only put huge demand on aerobic systems, but also the need for speed and agility in game situations. In a comprehensive study of field hockey, Anders and Mayers [37] found that a player with fast and efficient movement can be the best player throughout the game of hockey. It was closely intertwined with strength and power components. In a recent study, ${ }^{31}$ reported that muscular strength and power development can help individuals in making all the movements more easily and effectively. In addition, Chris et al, [38] firmly stated that, a focus on strength and power training will ensure players to be in very satisfying physical condition and able to avoid injuries, as well as providing a very positive relationship with fitness performance such as acceleration and change of direction.

The present study was designed to determine the effectiveness of post-activation potentiation training on power production performance. One interesting findings is power production performance furnishes significant improvement after moving over 16 session ( 8 weeks) of post-activation potentiation training. The percentage for CMJ test showed huge difference in pre-test and post-test between PAP group and control group. The PAP group pointed out $19 \%$ increment better than control group with only $3 \%$ increase. These results corroborate the ideas of Mc Donald et al [39] who suggested that post-activation potentiation training revealed significant increase in power production. The researchers used 30 people who are active in sports and took 6 weeks in their study. They made comparisons between 3 different training groups (PAP group, Resistance Group, and Plyometric Group). As a result, PAP group showed a good impact in the vertical jump height, peak ground reaction force, and increase peak power.

In the same vein, Mihalik et al [40], in their article entitle 'comparing short-term complex and compound training programs on vertical jump height and power output' noted that both group training significantly improved their vertical jump height and power. They took 4 weeks and used college players as the subject of the study. As a result, 4 weeks of PAP training provided an increase of $5.4 \%(\mathrm{~cm})$ and $4.8 \%$ (power).

However, there is also a study that disagrees with the above findings. Jones and Lees [41] argued that PAP training did not give any significant stimulus to CMJ performance. The study used 4 sets of 5 repetition squats at $85 \%$ of $1 \mathrm{RM}$ with different resting time. This view is supported by Scott and Docherty [42] who wrote about the effects of heavy preloading on vertical and horizontal jump performance. This study required the subjects to perform all the tests given as familiarization session. The aim was to give the subject a comfortable feel to the test. After that, a total of four training sessions were conducted. Among the exercises were back squat, vertical jump and horizontal jump. After 
familiarization session, subjects (resistance trained-men) performed 5RM single repetition back squat with 5 minutes of resting time. However, performance jumping did not show any significant change. However, this study is not a highly statistical study. It has been concluded that no evidence is available to support the experimental hypothesis although the absence of treatment effects cannot be excluded.

Looking at past research results, it can be concluded that some important elements need to be considered in the aspect of activating PAP's role in physical performance. Based on Seitz and Haff [43] study that used heavy weight lifting (87\% - 93\% of $1 \mathrm{RM})$, the need for resting time between 4 to 12 minutes and training status (experience in weight training) are important factors in activating jumping performance. Most importantly, this also facilitates neuromuscular adaptation to strength training. This is strongly supported by Bompa and Buzzichelli [44] which reported that when the body gets a quality strength training period and good training intensity, more recruitment muscle fibers are produced. Ultimately, the stimulus towards power performance improvements will take effect. By using the concept of periodization, this current study is more relevant and practical in improving and maintaining the lower body power production of the players.

\section{Conclusion}

In conclusion, this study managed to point out about the uniqueness of PAP training that can affect the physical fitness performance. By holistically understanding the basic needs of hockey game and the mechanisms of PAP's existence, it is able to produce positive results against hockey players.

In addition, the focus of research is not only on theoretical, but also solving the problems that occur in the use of PAP training. Apparently, there were difference in ideas and findings about PAP training. For that reason, the current study presented 3 objectives to answer the questions that arose. Finally, the results of this writing can provide an additional useful knowledge to athletes, coaches, and the public. This writing is not only about theoretical knowledge, but also applies to practical knowledge that gives users ideas and options to do a strength training program.

\section{References}

[1] Gullich, A, and Schmidtbleicher, D. (1996). MVC-induced shortterm potentiation of explosive force. New Studies in Athletics, 11, $67-81$

[2] Robbins D.W. (2005). PAP and its practical applicability: a Brief Review. Journal of Strength and Conditioning Research, 19(2), 453-458.

[3] Alexander P. Harrison. (2011). PAP: Predictors in NCAA Division II Varsity Track and Field Power Athletes.

[4] Chad Ethan Smith. (2014). the Effect of PAP warm-up on subsequent sprint performance, University of Utah, United States

[5] Robin Healy \& Thomas M. Comyns. (2017). the Application of post activation potentiation methods to improve sprint speed. Journal of Strength and Conditioning, 39(1), 1-9.

[6] Laurent B. Seitz, Minas A. Mina \& G. GGregory Haff. (2016). Post activation potentiation of horizontal jump performance across multiple sets of a contrast protocol. Journal of Strength and Conditioning Research, 30(10), 2733-2740.

[7] Turner AP, Bellhouse S, Kilduff LP \& Russell M. (2015). Pos activation potentiation of sprint acceleration performance using plyometric exercise. Journal of Strength and Conditioning Research, 29(2), 343-350.

[8] Nilo M, Valmor T, Salomao B, Romulo B, Alexandre M and Maria A.P.D. (2013). Post-activation potentiation on RSA in elite handball players. Journal of Strength and Conditioning, 27(3), 662668.

[9] Okuno NM, Tricoli V, Silva SB, Bertuzzi R, Moreira A \& Kiss MA. (2013). Post activation potentiation on repeated sprint ability in elite handball players. Journal Strength Conditioning Research, $27,662-668$
[10] Hilfiker R, Hubner K \& Lorenz T. (2007). Effects of drop Jump added to the warm-up of elite-sport athletes with a high capacity for explosive force development. Journal of Strength and Conditioning Research, 21(2), 550-555.

[11] Laurent B. Seitz and G. Gregory Haff. (2015). Factors modulating post activation potentiation of jump, sprint, and throw and upper body ballistic performance: A systematic Review with metaanalysis. Sport Medicine, 46(2), 2331-40.

[12] Hodgson M, Docherty D, Robbins D. (2005). PAP underlying physiology and implications for motor performance. Sport Medicine, 35(7), 385-395.

[13] Steven T. Banks. (2016). Post activation potentiation: Practical Implications in the collegiate settings. University of Montana, Missoula, United State.

[14] Hamada T, Sale D.G, \& MacDougall J.D. (2000). PAP in endurance-trained male athletes. Medicine \& Science in Sports Exercise, 32(2), 403-11.

[15] Rixon KP, Lamont HS, Bemden MG. (2007). Influence of type of muscle contraction, gender and lifting experience on PAP performance. Journal of Strength and Conditioning Research, 21(2), 500-505.

[16] Chiu LZ, Fry AC, Weiss LW, Schilling BK, Brown LE \& Smith SL. (2003). PAP response in athletic and recreationally trained individuals. Journal of Strength and Conditioning Research, 17(4), 671-677.

[17] Danielle Reardon. (2013) Do changes in muscle architecture effect post-activation potentiation. University of Central Florida, United States of America

[18] Tudor Bompa \& Carlo A. Buzzichelli. (2015). Periodization Training for Sports ( $3^{\text {rd }}$ Edition). United States: Human Kinetics.

[19] Santos EJM \& Janeira MAAS. (2008). Effects of complex training on explosive strength in adolescent male basketball players. Journal of Strength Conditioning Research, 22, 903-909.

[20] Ebben. WP. (20020. Complex training: A brief review. Journal Sports Science Medicine, 1, 42-46.

[21] Burger. T. (1999). Complex training compared to a combined weight training and plyometric program. Physical Education. University of Idaho Moscow.

[22] Apel Jm, Lacey RM \& Kell RT. (2011). A comparison traditional and weekly undulating periodized strength training programs with total volume and intensity equated. Journal of Strength and Conditioning Research, 25 (3), 694-703.

[23] Kell RT. (2011). The influence of periodized resistance training on strength changes in men and women. Journal of Strength and Conditioning Research, 25 (3), 735-744.

[24] Rhea MR, Phillips WT \& Burkett LN. (2003). A comparison of linear and daily undulating periodized programs with equated volume and intensity for local muscular endurance. Journal of Strength and Conditioning Research, 17 (1), 82-87.

[25] Rhea MR, Ball SD, Phillips WT \& Burkett LN. (2002). A comparison of linear and daily undulating periodized programs with equated volume and intensity for strength. Journal of Strength and Conditioning Research, 16 (2), 250-255.

[26] Apel JM, lacey RM \& Kell RT. (2011). A comparison of traditional and weekly undulating periodized strength training programs with total volume and intensity equated. Journal of strength and conditioning research, 25 (3). 694-703.

[27] Baker, D, Wilson \& G, Carlyon R. (1994). Periodization: the effect on strength of manipulating volume and intensity. Journal of strength and conditioning research, 8 (4). 235-242.

[28] Smith, R.A., Martin, G.J., \& Szivak, T.K. (2014). The effects of resistance training prioritization in NCAA Division I Football summer training. Journal of strength and conditioning research, 28 (1). 14-22.

[29] Jose Manuel Vilaca Maio Alves, Antoniio Natal Rebelo, Catarina Abrantes \& Jaime Sampaio. (2010). Short-term effects of complex and contrast training in soccer players' vertical jump, sprint and agility. Journal of Strength and Conditioning, 24(4), 936-941.

[30] Barun Hanjabam \& Jyotsna Kailashiya. (2014). Effects of addition of sprint, strength and agility, training on cardiovascular system in young male field hockey players: An echocardiography based study. Journal of Sports and Physical Education, 1(4), 25-29.

[31] Kassim, M., Ahmad, K., \& Bahari, B. (2016). Konsep latihan dalam sukan. Pekan Ilmu. Selangor

[32] Dodd, D.J., \& Alvar, B.A. (2007). Analysis of acute explosive training modalities to improve lower-body power in baseball players. Journal of Strength and Conditioning Research, 21, 1171182.

[33] Seitz. L., Trajano, \& Haff, G. (2014). The back squat and the power clean: elicitation of different degrees of potentiation. International 
Journal Sports Physiology Performance, 9, 643-649.

[34] Bevan, H.R., Cunningham, D.J., Tooley, E.P., Owen, N.J., Cook, C.J., \& Kilduff, L.P. (2010). Influence of post-activation potentiation on sprinting performance in professional rugby players. Journal of Strength and Conditioning Research, 24, 701-705.

[35] Lim, J.J., \& Kong, P.W. (2013). Effects of isometrics and dynamic post-activation potentiation protocols on maximal sprint performance. Journal of Strength and Conditioning Research 27(10), 2730-2736.

[36] Weyand, P.G., Strenlight, D.B., Bellizzi, M.J., \& Wright, S. (2000). Faster top running speeds are achieved with greater ground forces not more rapid leg movements. Journal of Applied Physiology, 89, 1991-1999.

[37] Anders, E., \& Myers, S. (2008). Field Hockey: Steps to Success. 2nd Edition, Human Kinetics Publishing, Champaign, Illinois.

[38] Chris Bishop, Jon Brazier, Jon Cree, \& Anthony Turner. (2015). A need analysis and testing battery for field hockey. Professional Strength and Conditioning, 36, 15-26.

[39] McDonald, C.J., Lamont, H.S., \& Garner, J.C. (2011). The effects of 3 different modes of training upon measures of $\mathrm{CM}$. performance. Journal of Strength and Conditioning Research, 25.

[40] Mihalik, J.P., Libby, J.J., Battaglini, C.L., \& McMurray, R.G. (2008). Comparing short-term complex and compound training programs on vertical jump height and power output. Journal of Strength and Conditioning Research, 22, 47-53.

[41] Jones, P., \& Lees A. (2003). A biomechanical analysis of acute effects of complex training using lower limb exercise. Journal of Strength and Conditioning Research, 17, 694-700.

[42] Scott, S.L., \& Docherty, D. (2004). Acute effects of heavy preloading on vertical and horizontal jump performance. Journal of Strength and Conditioning Research, 18, 201-205.

[43] Seitz, L.B., \& Haff, G. (2015). Factors modulating post-activation potentiation of jump, sprint, throw, and upper-body ballistic performance: A systematic review with meta-analysis. Sports Medicine, 46, 231-240.

[44] Bompa, T., \& Buzzichelli, C.A. (2015). Periodization training for sports (3rd Ed.). United States: Human Kinetics. IL. 